\title{
Measuring sensitivity of two OSPAR indicators for a coastal food web model under offshore wind farm construction
}

Raoux Aurore 1, 2, * , Lassalle Géraldine ${ }^{3}$, Pezy Jean-Philippe ${ }^{2}$, Tecchio Samuele ${ }^{1}$, Safi Georges ${ }^{1}$, Ernande Bruno ${ }^{4}$, Mazé Camille ${ }^{5}$, Le Loc'h François ${ }^{5}$, Lequesne Justine ${ }^{6}$, Girardin Valérie ${ }^{7}$, Dauvin Jean-Claude ${ }^{2}$, Niquil Nathalie ${ }^{1}$

${ }^{1}$ Normandie Univ, UNICAEN, Biologie des ORganismes et Ecosystèmes Aquatiques BOREA (MNHN, UPMC, UCBN, CNRS-7208, IRD-207) CS 14032, 14000 Caen, France

${ }^{2}$ Normandie Univ, UNICAEN, UMR M2C (UCBN, UR, CNRS-6143), 24 rue des Tilleuls, 14000 Caen Cedex, France

3 IRSTEA, UR EABX (Aquatic Ecosystems and Global Changes), 50 avenue de Verdun, 33612 Cestas

Cedex, France

4 IFREMER, Laboratoire Ressources Halieutiques, 150 quai Gambetta, BP 699, 62321 Boulogne sur Mer, France

${ }^{5}$ Laboratoire des Sciences de l'Environnement Marin, UMR 6539 LEMAR (CNRS/UBO/IRD//fremer), Institut Universitaire Européen de la Mer (IUEM), Technopôle Brest-Iroise, Rue Dumont d'Urville, 29280 Plouzané, France

${ }^{6}$ Centre Henri Becquerel, Unité de recherche clinique, Rue d'Amiens, CS 11517, 76038 Rouen Cedex

1, France

${ }^{7}$ Normandie Université UNICAEN, UMR 6139, Laboratoire de Mathématiques Nicolas Oresme, BP 5186, 14032 Caen, France

* Corresponding author : Aurore Raoux, email address : aurore.raoux@unicaen.fr

\begin{abstract}
:
A combination of modelling tools was applied to simulate the impacts of the future Courseulles-sur-mer offshore wind farm (OWF) construction (Bay of Seine, English Channel) on the ecosystem structure and functioning. To do so, food-web models of the ecosystem under three scenarios were constructed to investigate the effect caused by the OWF of added substrate (reef effect), fishing restriction (reserve effect), and their combined effect. Further, Ecological Network Analysis indices and Mean Trophic Level were derived to investigate their suitability for detecting changes in the ecosystem state. Our analysis suggests changes in the ecosystem structure and functioning after the OWF construction, the ecosystem maturity was predicted to increase, but no alterations in its overall resilience capacity.
\end{abstract}




\section{Graphical abstract}

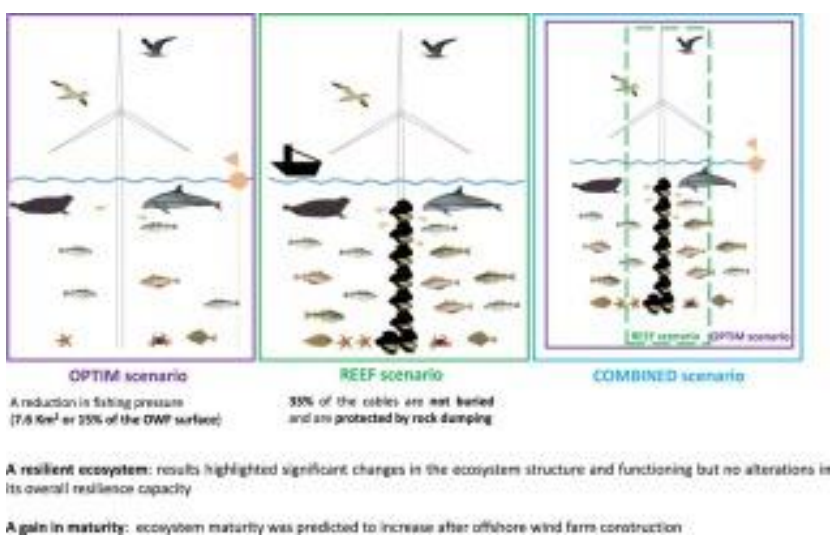

\section{Highlights}

Ecopath models before/after offshore wind farm were built. ENA indices revealed significant changes in ecosystem structure and functioning. Ecosystem maturity was predicted to increase after offshore wind farm construction.

Keywords : Ecopath with Ecosim, Ecological Network Analysis, Reef effect, Reserve effect, Mean Trophic Level, Marine renewable energy 


\section{INTRODUCTION}

In order to reduce carbon emissions, there is a worldwide transition of the energy production scheme from fossil fuels to renewable energy sources. Furthermore, there is currently in Europe a strong political drive for the development of Marine Renewable Energies (MRE). For instance, the European Union (EU) Renewable Energy Directive (2009) has set a common target for $20 \%$ of EU's energy to come from renewable sources by 2020. As a consequence, the development of Offshore Wind Farm (OWF) projects along the coast of France is rapidly increasing. Three successive calls for tenders related to OWF development have been successively announced, and seven sites have been selected for future OWF construction. Among them, three should be built in the Eastern English Channel: in Fécamp, Dieppe-LeTréport, and Courseulles-sur-mer. Beyond the fact that the English Channel is the current hotspot for OWF development in France (Raoux et al., 2017), it is also a significant economic area already subjected to multiple anthropogenic perturbations such as pollution, transport, fishing, aquaculture, aggregate extraction, and sediment dredging and deposit (Dauvin, 2012; 2015).

Development of OWF installations across the Eastern English Channel will lead to the introduction of hard substrates in the natural soft sediments, which is expected to cause changes in the benthic community in the vicinity of the turbines (Coates et al., 2014). In fact, these hard substrates are likely to be used directly as habitats by several epibenthic and benthic species, and to attract a new suits of species, including non-native ones (Wilhelmsson and Malm, 2008; Maar et al., 2009). Previous studies made in the Baltic and North seas showed that filter feeders such as mussels and amphipods tended to dominate on the turbine vertical structures, while benthic predators such as crabs dominate on the foundation base and the score protections (Wilhelmsson et al., 2006; Krone et al., 2017). This aggregation of epibenthic and benthic organisms on the turbine foundations is known as the "reef effect" and is considered as one of the most important effects on the ecosystem generated by OWF construction (Petersen and Malm, 2006; Langhamer, 2012). Besides the "reef effect", spatial restrictions in form of fisheries exclusion zones (e.g. bottom trawl and dredge) are likely to be implemented around turbines and cables for navigation safety. These two fishing activities are known to be major threats to benthic organisms and their associated habitats (Thurstan et al., 2010; Turner et al., 1999). A possible exclusion of fishing activities inside the OWFs could act as local Marine Protected Areas (MPAs) (Shields et al., 2014). MPAs are known to cause "reserve effect" which can lead to increased local biomasses (Leonhard et al., 2011; Lindeboom et al., 2011; Shields et al., 2014) and possible changes in the food-web structure. However, until now, it has seemed difficult to separate effects of fisheries exclusion from the "reef effect" in field (Bergström et al., 2014). Clearly, solutions set to mitigate the impacts of climate change will have consequences on biodiversity and ecosystem functioning. Therefore, an important challenge for the scientific community is now to assess the range of the possible ecological consequences before project implementations (or decisions) to optimize the targeted objectives. The Marine Strategy 
Framework Directive (MSDF) (EU, 2008) stresses the urgent need of development, tests and validation of ecosystem health indicators. The ecosystem approach is explicitly developed and applied with the aim of attaining Good Environmental Status (GES) of ecosystems. The directive's recent revision (EU, 2017) has even emphasized the importance of considering marine ecosystem's structure, functions and processes to achieving GES. Further, MSFD has suggested to develop more integrative and process-oriented food-web indicators (Rombouts et al., 2013). The OSPAR convention (an international cooperation on the marine environmental protection of the North East Atlantic) has proposed a list of food-web indicators which would capture the emerging properties of the food web (Niquil et al., 2014). The ENA indices are among these indicators, but they are not yet considered as "operational" and cannot be used in the assessment of the marine environmental status.

For several years, the "reef effect" has only been investigated on benthic and fish species alone, but never with a holistic approach to assess its potential impacts on the ecosystem taken as a whole. Recently, Raoux et al. (2017) explored a new way to look at the potential impacts of OWFs through food-web models and flow analysis. They used the Ecopath with Ecosim (EwE) approach (Polovina, 1984; Christensen and Walters, 2004; Christensen et al., 2008) to model the trophic web at Courseulles-sur-mer OWF site. This approach, in which all biotic components of the system can be considered at the same time, is useful to gain a better understanding of the ecosystem structure and functioning, and for predicting how it may change over time when facing perturbations (Plagànyi, 2007). Then, Raoux et al. (2017) used the Ecosim model (the temporal dynamic module of EWE) to project the evolution of the ecosystem over the next 30 years after an expected increase in biomass of some targeted benthic and fish compartments in relation to the OWF construction. Ecological Network Analysis (ENA) indices (Ulanowicz, 1986) were further calculated, summarising the emergent properties of the ecosystem, giving indications about the possible state of the ecosystem at the end of the simulation. Among the core conclusions were (1) that the total ecosystem activity, the overall system omnivory, and the recycling should increase after the OWF construction, and (2) that some higher trophic levels (i.e. exploited piscivorous fish species, endangered marine mammals) are very likely to respond positively to the biomass aggregation on the scour protections of the piles and turbines. Even if the study of Raoux et al. (2017) strongly suggested that the ecosystem structure and functioning would experience changes in response to the OWF construction, before/after statistical comparisons were not possible as outputs from the Ecopath model and Ecosim simulation were only providing one value per ENA index. The authors emphasized the need to quantify the uncertainty in the ENA indices in order to produce robust conclusions on the ecosystem functioning, and thereby better predict its responses to disturbances. 
The objective of the current study was to investigate the usefulness of ENA indices in the assessment of the state of the ecosystem by confronting them to a complementary indicator developed under the OSPAR commission, the Mean Trophic Level (MTL), which is considered as operational and was used in the OSPAR 2017 intermediate assessment (www.ospar.org). Following the modelling procedure in Raoux et al. (2017), the present study is intended to further deepen our understanding of the OWF construction effect on the ecosystem by:

- the increase in number of plausible scenarios: simulations of both the "reef effect" and the "reserve effect" on the ecosystem will be performed, as well as their combined effect;

- the comparison of ENA indices to "traditional" indicators such as MTL;

- the quantification of the uncertainty in the ENA indices: this will strengthen our interpretation of these indices by allowing to statistically test the differences between the scenarios in terms of predicted ecosystem functioning. This will be performed using the ENAtool routine generating probability distributions for ENA indices at the end of each simulation run (Guesnet et al., 2015);

- discussing our results in the scope of the theory of ecological stability (Holling, 1996)

\section{MATERIAL AND METHODS}

\subsection{Study area}

The OWF will be built in the next years in the Bay of Seine (English Channel eastern part) which forms a roughly $5000-\mathrm{km}^{2}$ quadrilateral. The Bay of Seine never exceeds $30 \mathrm{~m}$ in depth. The maximum speed of the tidal currents is around 3 knots in the north of the bay (Salomon and Breton, 1991; 1993). The tidal currents play an important role in distributing both sediments and benthic communities (Larsoner et al., 1982; Gentil and Cabioch, 1997). The dominant offshore sediments are pebbles, gravels and coarse sands, while the inshore sediments are mostly fine sands and muddy fine sands (Dauvin et al., 2007; 2015).

\subsection{Courseulles-sur-mer Offshore Wind Farm}

The Courseulles-sur-mer OWF will be located 10 to $16 \mathrm{~km}$ offshore from the Calvados coast at a depth of 22 to $30 \mathrm{~m}$. It will be located on the coarse sand and pebbles benthic communities of the Bay of Seine (Fig. 1). The OWF will represent an area of $50 \mathrm{~km}^{2}$. The 75 turbines (each $6 \mathrm{MW}$ ) capable of producing $450 \mathrm{MW}$ will be installed by Eoliennes Offshore du Calvados" (EOC) (a subsidiary of Éolien Maritime France (EMF) and wpd Offshore) in the next years.

In the Environmental Impact Assessment (EIA), EOC proposed two scenarios. In the first scenario, the 75 monopiles and the converter station will require scour protections. In addition, $33 \%$ of the cables will be 
129 rock-dumped. In the second scenario, $7.6 \mathrm{~km}^{2}$ or up to $15 \%$ of the total surface of the Courseulles-sur-mer 130 OWF will be closed to fishing for safety measures. Thus, the active gears will be banned $150 \mathrm{~m}$ around the 131 cables whereas the passive gears will be not banned around them and both the passive and active gears will be banned around the substation.

\subsection{The pre-existing Ecopath model}

The Ecopath with Ecosim (EwE) approach was retained by Raoux et al. (2017) to estimate the value of all carbon flows in the food-web at the Courseulles-sur-mer OWF site. This Ecopath model was composed of 37 compartments, from primary producers (phytoplankton) to top predators (seabirds). The calculated Pedigree index for this model called model "Before the implantation of the OWF" or BOWF was 0.523.

Details about the functional group composition, a detailed description of the Ecopath with Ecosim approach (Christensen and Walters, 2004; Christensen et al., 2008), and the main equations are given in Raoux et al. (2017).

2.4 Time dynamic simulations: the "reef effect" and "reserve effect" due to the OWF implantation Ecosim is the EwE temporal module which allows to re-calculate the initial Ecopath snapshot model for each time-step, taking into account a series of variations in the input parameters such as fishing effort or biomass accumulation. In this study we analysed three different scenarios using EwE. For the first scenario, we used the work by Raoux et al. (2017), who ran the Ecosim module to analyse the potential impacts on the ecosystem of benthic and fish aggregations inside the OWF ecosystem (REEF scenario). In the REEF scenario, expected biomasses were calculated for species that would presumably profit from the "reef effect" (Koller et al., 2006; Reubens et al., 2011; Krone et al., 2013; Reubens et al., 2013) by multiplying the average biomass per $\mathrm{m}^{2}$ found in the literature for the respective species by the surface area represented by the turbine foundations and scour protections, and divided by the total OWF area. A temporal simulation was then run over 30 years while forcing the biomasses to increase for the targeted species compartments, and while keeping the original biomass values for the other functional groups. At the end of the simulation, an Ecopath model was derived and ecosystem flows and indices were calculated. More details are given in Raoux et al. (2017).

In the present study, the same methodology as in Raoux et al. (2017) was followed for the REEF scenario.

158 But, two more scenarios were applied: (1) by decreasing the fishing pressure (OPTIM scenario) in accordance with what is proposed by the OWF owners in the EIA in order to "optimize" the area for fishing activities; (2) 
by combining the REEF scenario developed by Raoux et al. (2017) and the OPTIM scenario developed in this

161 study into one (COMBINED scenario).

163 For the OPTIM scenario, a temporal simulation was run over 30 years with a reduction in fishing pressure inside the OWF. In this scenario, $7.6 \mathrm{~km}^{2}$ or $15 \%$ of the total surface of the Courseulles-sur-mer OWF was closed to fishing. Landings of species that would presumably profit from this decrease in fishing pressure, such as king scallop, European plaice, sole, other flat fish, sea bream, pouting, Atlantic cod, sharks and rays, European sea bass, mackerel, benthic and benthopelagic cephalopods were changed accordingly. The Ecosim model was run with the new landings values ( $-15 \%$ of the initial landing values of the BOWF model) for the targeted groups listed above as the only variations taken into account to drive the evolution of the system through time. Benthic and fish catches were obtained from the IFREMER Fisheries Information System (http://sih.ifremer.fr/). For more information about the landing data please see Raoux et al. (2017).

For the COMBINED scenario, we combined the assumptions from the REEF and the OPTIM scenarios, as detailed above.

For these two new scenarios, we extracted, from the Ecosim simulation, a new Ecopath model at the end of the 30 years' simulations, to compare the situation described in the BOWF model to the one after the construction of the OWF (OPTIM and COMBINED simulations). We followed the same balancing procedure as presented in Raoux et al. (2017).

\subsection{Linking ecosystem health with two types of OSPAR indicators} Recently, there has been a growing interest and need for robust ecological indices to evaluate ecosystem status. Several indicators are being developed by the OSPAR Commission to protect and conserve marine ecosystems. These include the Mean Trophic Level (MTL) which has been adopted as a common indicator (i.e. commonly adopted by several OSPAR Member States) and the ENA indices which are candidate indicators (i.e indicators that are still being developed and tested prior to potential adoption by OSPAR Member States). In the current study, the suitability of ENA indices to assess the ecosystem's state was investigated, confronting them to two other OSPAR indicators, namely the Mean Trophic Level and the Biomass of the Groups. 


\subsubsection{OSPAR common Indicator (The Mean Trophic Level)} The MTL, an indicator from the OSPAR food-web list of indicators (Niquil et al., 2014), was used to describe changes in the structure of the food web following the OWF construction. Using outputs of functional groups' biomass and trophic levels derived from the three scenarios, MTL was calculated as the weighted average trophic level for functional groups following the equation:

$$
M T L=\frac{\sum_{i} T L \mathrm{i} B \mathrm{i}}{\sum_{i} B \mathrm{i}} \quad(\text { Eq. } 1)
$$

where $T L_{i}$ and $B_{i}$ are the trophic level and the biomass of each functional group, respectively. According to Shannon et al. (2014), three MTL were calculated for each scenario, in order to capture (1) the whole community of consumers (MTL_2.0) with a cut-off of functional groups with a Trophic Level $(T L)<2$ (i.e: primary producers and detritus were not taken into account); (2) the higher trophic levels species (MTL_3.25) excluding functional groups with $T L<3.25$; and (3) the top predators (MTL_4.0) excluding functional groups with $\mathrm{TL}<4.0$.

\subsubsection{Candidate Indicators (the Ecological Network Analysis indices)}

Ecological Network Analysis indices (ENA, Ulanowicz, 1986) were used to compare the ecosystem structure and function before and after the OWF installation. The following structural ENA indices namely Total System Throughput (T.., Latham, 2006), Ascendency (A, Ulanowicz, 1997, relative Ascendency (A/C, Ulanowicz et al., 2009), Redundancy (Ulanowicz, 1986; 1997), relative redundancy (R/C, Ulanowicz et al., 2009), System Omnivory Index and Transfer Efficiency (TE, Lindeman 1942) as well as the following functional ENA indices namely Finn's Cycling Index were retained (FCl, 1980). More details were given in Raoux et al. (2017).

Finally, two more ecosystem attributes were characterized by the following ratios: the total primary production/total respiration (PP/R) and total biomass/total system throughputs (B/T..)

The network analysis plug-in included in EwE (Christensen and Walters, 2004) was used to calculate the ENA indices for the BOWF, REEF, OPTIM and COMBINED models.

\subsection{Statistical analysis on the ENA indices}

Ecopath is a single solution model and so statistical comparisons between models were not possible. The ENAtool routine (Guesnet et al., 2015) was built to incorporate uncertainty around input parameters and provided ENA index distributions that can be statistically compared between models. This tool is resampling multiple balanced input matrices and calculating a set of ENA indices for each one. To do so, for each input 
parameter of the BOWF Ecopath model, an uncertainty interval based on the EWE pedigree routine was 217 allocated. In fact, EwE presents a pedigree routine that allows modellers to quantify the input parameter 218 quality and associates a confidence interval according to predefined tables (Christensen and Walters, 2004). 219 Here, a set of 50 balanced models were sampled with input parameters boundaries defined as in Table 1. 220 The same was completed with the REEF, OPTIM and COMBINED models. As the models were highly 221 constrained (i.e. EE close to 0.99 for many groups), computational time to generate balanced input matrices was extremely high. As such, the set was limited to 50 in the present study which corresponded already to several millions of trials to obtain the number of solution obeying our constraints. As probability distributions were generated for each index in the four models, it was now possible to test the significance of differences between models.

$<$ Table 1>

Considering that the ENA indices distributions generated by the ENAtool routine were unpaired, statistical differences between these ENA indices distributions of the BOWF model and the three scenarios were obtained by testing whether ENA indices means differed from zero following permutation tests. In fact, the permutation method is a non-parametric test which means that unlike popular parametric test like ANOVAs, it does not make specific assumption about the shape of population distribution from which the observation has been derived (Groope et al., 2011). It assumes only that the observation is exchangeable. Thus, ENA indices distributions were randomized across the model and the three scenarios. However, as we tested several times the same hypothesis for non-independent indices, the maximum-statistic method for multiple comparisons (also called minimal p-value method for multiple comparisons) (Nichols et al., 2003; Groppe et al., 2011). This method, like Bonferroni correction, allows to control the probability that one or more false discoveries is made during the multiple comparison (Groope et al., 2011). It also allows to take into account the multiplicity of testing but also to keep the correlation structure between the indices. With this method, all the indices were compared at the same time (multiple comparisons). For that, each ENA indices was standardized by removing by its mean and by dividing its standard deviation, thus the unit of all the ENA were the same. One thousand randomization samples were carried out. Significant values were then determined by comparing the distributions obtained to the ENA indices means before randomization. Results are presented in Table 3, significant value (pvalue $<0.05$ ) are indicated in bold.

\section{Results} The ecosystem structure and functioning before OWF construction (i.e. BOWF model) have already been described in Raoux et al. (2017). The BOWF model and the REEF scenario were used unchanged in the present paper. The 4 balanced trophic webs included 37 functional groups. 


\subsection{Trophic levels and biomass profiles}

The trophic levels of the functional groups ranged from $T L=1$ for primary producers and detritus, to a maximum of 4.8 represented by marine mammals (i.e. by grey seals in the BOWF model and OPTIM scenario, and by bottlenose dolphins in the REEF and COMBINED scenarios) (Table 2). Most functional groups maintained approximately the same trophic level between the different scenarios.

The biomass by trophic levels exhibited a similar pattern between the BOWF model and the three scenarios, with the majority of the biomass being concentrated at TL 2 (Table 2). These high biomasses were mainly related to bivalves in the BOWF model and the OPTIM scenario, and more specifically, to bivalves and benthic predators in the REEF and COMBINED scenarios. The REEF and COMBINED scenarios exhibited also a higher biomass of benthic invertebrates compared to the BOWF model and the OPTIM scenario.

A comparison between the compartmental throughflows (the amount of energy going through a compartment in terms of carbon) between the BOWF model and the three simulated scenarios were done to understand how the system changed after the OWF construction. The BOWF model compared to the REEF scenario showed: 1) an increase in top predators activity (except for diving seabirds), elasmobranchs, Atlantic cod, whiting, pouting, European sprat, sea bream, flatfish, benthic invertebrate predators, filter feeders and bivalves; 2 ) a decrease in benthic invertebrate deposit feeders, suprabenthos and King Scallop (Fig. 2). The comparison between the BOWF model and the COMBINED scenario differed from the previous comparison for the following compartments: mackerel, sea bass and King Scallop which showed an increase in their activity (Fig. 2). Finally, the comparison between the BOWF model and the OPTIM scenario differed from the two previous comparisons as 1) the activity of the lower trophic levels (zooplankton, bacteria, suprabenthos) and some top predators (cetaceans, cephalopods) had increased, and 2) the activity of benthic invertebrate filter feeders, sea bream, sprat, pouting, and whiting decreased (Fig. 2).

<Figure: 2>

\subsection{MTL comparisons between scenarios}

A change in the food web structure was observed when simulating the "reef effect". This applied to both the REEF and COMBINED scenarios that registered a decrease in the MTL compared to the BOWF and OPTIM situations (Fig. 4). Firstly, when considering the whole consumers' community (i.e. MTL_2.0), a decrease of 0.1 in the MTL was noticed, which seemed to be driven by the important increase in the benthic bivalves' biomass $\left(T L=2.1\right.$. Bivalves doubled their biomass from around $19 \mathrm{gC} \cdot \mathrm{m}^{-2}$ in the BOWF and OPTIM scenarios to more than $40 \mathrm{gC} \cdot \mathrm{m}^{-2}$ in the REEF and COMBINED scenarios (Fig. 3). The important increase of bivalves' biomass went along with an increase in the biomass of the benthic filter feeders and a decrease in the 
biomass of a higher TL functional group (i.e. European pilchard), which strengthened the decrease in the 280 global MTL. Secondly, after excluding the low trophic level species (i.e. MTL_3.25), the decrease in the MTL 281 was even more marked (more than 0.3 decrease in MTL) between BOWF-OPTIM and REEF-COMBINED. This 282 decrease was not influenced anymore by the bivalves' biomass change as this functional group was excluded. 283 The main functional groups driving the MTL_3.25 trend (i.e. functional groups representing $95 \%$ of the total 284 biomass) were exclusively fish functional groups (Fig. 3). Within these functional groups, two of them showed 285 a marked shift between BOWF-OPTIM and REEF-COMBINED. The pouting biomass doubled but, in the same 286 time, its TL decreased (i.e. TL of pouting decreased from 3.7 in BOWF-OPTIM to 3.3 in REEF-COMBINED, see 287 Table 2). The combination of a biomass increase and a TL decrease resulted in a decreasing trend of the 288 MTL_3.25. In this case, the change in the TL of pouting between scenarios highly influenced the MTL trend. 289 Indeed, when applying a unique mean TL value for all scenarios (TL mean between the different scenario for 290 each group), the decrease in MTL between BOWF-OPTIM and REEF-COMBINED was significantly reduced. 291 The MTL decrease was also stressed by the important decrease in the relative biomass of piscivorous fish (TL 292 = 3.8). Thirdly, when focusing on top predators (i.e. MTL_4.0), the registered decrease in MTL trend was 293 around 0.1, similar to the observed decrease in MTL_2.0 (Fig. 3). The shark and rays functional group showed 294 an important increase in its biomass while a decrease in the TL of this functional group was observed between 295 BOWF-OPTIM and REEF-COMBINED (Table 2). Again, the combination between biomass increase and TL 296 decrease has resulted in a decreasing trend of the MTL_4.0. The MTL decreasing trend at the three cut-offs 297 (i.e. MTL_2.0, MTL_3.25 and MTL_4.0) was thus driven by an important restructuration of functional groups' 298 biomass with the "reef effect" coupled to the modification of the functional groups' TL in relation to the 299 simulated scenarios.

\subsection{ENA indices and ecosystem attributes comparisons between scenarios} From a methodological perspective, the single ENA indices values derived from the EwE software for T.., A, $A / C, A M I, R, R / C$ were included in the distributions calculated by the ENAtool routine for the BOWF model and the three scenarios (Fig. 4). For the $\mathrm{FCl}$ index, the Ecopath point estimates were included in the distributions for the BOWF model and the OPTIM scenario and were above the upper boxplot whisker for the REEF and COMBINED scenarios. 
scenario as well as between the REEF and the OPTIM scenario. $R$ increased significantly between the BOWF model and the REEF scenario. A similar pattern was observed between the BOWF model and the COMBINED scenario as well as between the REEF and COMBINED scenarios. The ratio R/C increased significantly between the BOWF model and the COMBINED scenario as well as between the REEF and the COMBINED scenario. On the opposite, the AMI decreased significantly between the BOWF model and the COMBINED scenario as well as between the REEF and the COMBINED. Finally, no significant changes were noticed for the $\mathrm{FCl}$ index between the BOWF model and the three scenarios (Table 3).

$<$ Table 3>

The graph of the transfer efficiencies (TE) as function of the trophic level showed a similar pattern between the BOWF model and the three scenarios, decreasing with increasing TL in all models (Fig. 5). Nonetheless, values were lower in the REEF and COMBINED scenarios compared to the two other situations.

\section{$<$ Figure 5>}

Concerning the other ecosystem attributes, results showed that the total PP/R decreased between the BOWF model and both the REEF and COMBINED scenarios, by approximately 35\% (Table 4). The B/T.. increased between the BOWF model and both the REEF and COMBINED scenarios, by approximately $33 \%$ (Table 4).

$<$ Table 4>

\section{DISCUSSION}

\subsection{Methodological issues}

The Ecopath model of the Courseulles-sur-mer area was based on local, highly replicated, and detailed samplings (Raoux et al., 2017). The overall pedigree index (0.523) for this model fall into the upper range of pedigree values obtained for other published models, confirming the relatively low level of data uncertainty. Compared to what was done previously by Raoux et al. (2017), the moderate uncertainty around the input data were taken into account with the ENAtool routine when analysing the outputs of the model and scenarios (Guesnet et al., 2015). Thus, statistical comparisons between the BOWF model and the 3 scenarios was performed. It is worth noting that the ENAtool allows to calculate uncertainty only for the ENA indices. This methodology brought rather substantial differences to the conclusions. For instance, Raoux et al. (2017) found an increase of $40 \%$ of the $\mathrm{FCl}$ between the BOWF model and the REEF scenario. However, in the present paper, this difference appeared none significant. Nonetheless, from a methodological point of view, this 
routine needs further development, particularly to reduce the computation time through paralle calculations for highly constrained models. In addition, allowing to quantify the uncertainty around the changes in the initial parameters such as compartment biomass and TL of the functional groups would be a useful addition to this method.

\subsection{The MTL a good indicator to assess changes in trophic webs}

The MTL was first applied on fish landings' data by Pauly et al. (1998) which led to the famous concept of "fishing down the marine food webs". The rationale behind this indicator is that a decline in MTL values indicates a gradual transition in the food web from long-lived, high trophic level piscivorous fish, towards short-lived, low trophic levels such as invertebrates and planktivorous fish. The resulting shorter food chain reduces the food webs' complexity, increasing the systems' vulnerability to both natural and anthropogenic perturbations (CBD 2004, Pauly and Watson 2003). In the current study, the MTL was applied to describe the food-web structure under different scenarios after the implementation of an offshore wind farm. The MTL showed a decreasing trend between BOWF-OPTIM and REEF-COMBINED scenarios, for all tested cut-offs (i.e. MTL_2.0, MTL_3.25, MTL_4.0). However, the observed decrease in MTL was not due to the disappearance or reduction of higher trophic levels. The different MTL indices along with the functional groups' biomass, allowed to detect a reconstruction of the food web caused by the simulated "reef effect" (REEF and COMBINED scenarios), which induced an increase in the total biomass of lower trophic levels mainly (benthic invertebrates' filter feeders and bivalves). In this new configuration, the "reef effect" cascaded up to the higher trophic levels feeding on filter feeders, which also increased in biomass. However, their increase in biomass is clearly overwhelmed by the large biomass increase in filter feeders, which resulted in a decrease in the relative biomass of higher trophic levels and a reduced MTL as a consequence.

The MTL indicator and the "fishing down marine food webs" concept has largely been tested and applied in the world oceans, generally on large ecosystem scales (Pinnegar et al., 2002; Ainley and Pauly, 2014; Gascuel et al., 2016) and in global comparative approaches (Pauly et al., 1998; Pauly and Palomares, 2005). The application of MTL indicator on smaller geographical scales, such as the OWF scale, and in relation to OWF installation rather than direct fishing pressure impact, is rather rare. However, in most studies using the MTL indicator, TL values applied to calculate the indicator are generally unique values extracted from global databases such as Fishbase or Sealifebase (Froese and Pauly, 2017; Palomares and Pauly, 2017). The evolution of species TL according to the different scenarios was applied on MTL indicator in the current study which induced an increased sensitivity of the MTL indicator to the structural changes occurring in the ecosystem. Indeed, when a unique mean TL value per species was applied for all scenarios instead of using the various TL estimated by models in the various scenarios, the decrease in MTL trend between BOWFOPTIM and REEF-COMBINED was significantly reduced. The interpretation of changes in the MTL indicator 
371 should thus be made considering the geographical scale that is applied, the main human pressure that is 372 considered, and the accuracy of the TL estimates in regard to the potential spatial and temporal difference 373 in TL. In the OSPAR context, the appropriate geographical scale for integrating the various indicators is a 374 current issue under consideration (Elliott et al. 2017, Haraldsson et al. 2017). An indicator can be applied at 375 different geographical scales from large OSPAR regions to local subregional areas (Haraldsson et al. 2017). 376 Interpretation of the MTL at different spatial scales should be made with caution, as this study shows that a 377 decreasing trend in this indicator cannot be automatically translated as "unsustainable" status, but closer 378 evaluation of the underlying reason is needed, at least at the small OWF scale.

379 The importance of having regular and accurate trophic level estimations that reflect the changes occurring 380 in the food web was also highlighted in the current work. This emphasizes the importance of surveying the 381 evolution of TL estimation in order for the MTL to detect accurately the changes that occurs in the food web. 382 This has been highlighted previously (Bourdaud et al., 2016, Arroyo et al., 2017), and should be especially 383 applied when this indicator is to be used for assessing the marine environmental status under management 384 context.

385 In Heymans et al. (2014), the MTL was applied on worldwide food-web models along with ENA indices. These 386 authors observed that the reduced MTL values were related to reduce transfer efficiency (TE) and high 387 Ascendency (A) reflecting an energy efficient transfer up the food chain, with low omnivory but a food web 388 high organization which is in line with the present ENA results as detailed below.

\subsection{Ecosystem maturity and resilience: interpreting ratios and ENA patterns}

390 According to Odum (1969), ecosystems evolve towards maturity in a process that involves structural changes 391 that are orderly, directional and predictable. Odum stated that the PP/R ratio is a functional index of 392 ecosystem maturity, and is expected to be higher than 1 in immature systems, and tends to 1 as a system 393 matures. The estimated PP/R values of the BOWF model and the three scenarios exceeded 1, meaning that 394 they have not yet reached a mature stage. However, the PP/R values for the scenario related to a "reef effect" 395 (REEF and COMBINED) were lower (table 4), suggesting a more mature ecosystem under these scenarios. 396 These results are in line with the high $B / T$.. values in the REEF and COMBINED scenarios, which in fact, are 397 expected to increase as an ecosystem matures (Odum, 1971).

398 According to our model and scenarios thirty years after the implantation of the OWF, the reserve effect 399 seems to have a relatively limited overall impact on the ecosystem. In fact, changes in the ENA indices 400 between the BOWF model and the OPTIM scenario were not significant. This could be explained by the fact 401 that the area which would be closed to the fisheries would be too small to have a significant impact at the 402 ecosystem level. Meanwhile, significant changes were observed in the ENA indices between the BOWF model 
403

404

405

406

407

408

409

410

411

412

413

414

415

416

417

418

419

420

421

422

and the different "reef effect" scenarios (REEF and COMBINED), which may have potential consequences in terms of resilience of the system. The term resilience can refer to two different aspects of system stability: engineering resilience and ecological resilience (Holling, 1996). The "engineering resilience" concept assumes the existence of a local equilibrium; a system with a short return time to equilibrium will be more resilient than one with a longer return time (Pimm, 1984; Holling, 1996). On the other hand, a system might exist in more than one stable state, a condition called "multiple stable states". In this case, resilience would be defined as the measure of the pressure magnitude that can be absorbed before the system crosses a threshold and settles into another state. Holling (1996) called this second concept "ecological resilience". Here, to interpret the differences in ENA indices between the BOWF model and the REEF/COMBINED scenarios, we will focus on ecological resilience as it is more applicable to changes observed by ecologists (Gunderson, 2009).

It has been demonstrated that resilience for a system is strongly related to its structure and functioning (Chapin et al., 1997). ENA indices are therefore powerful tools as they link system architecture to system function, revealing the emergent properties (Ulanowicz, 2004). ENA indices have been calculated in several marine and coastal ecosystems to assess their trophic structure (Rybarczyk et al., 2003). In fact, under stressful conditions, the emergent properties of an ecosystem can change (Mukherjeer et al., 2015; Tecchio et al., 2015; Pezy et al., 2017). Ascendency increased significantly in the REEF and COMBINED scenarios. According to Ulanowicz (1986), this index allows to assess the development status or maturity of an ecosystem. Ulanowicz et al. (1997) stated that high values of Ascendency represent a mature system whereas low values indicate a stressed or immature system (Ulanowicz, 1997; Ortiz and Wolff, 2002; Patricio et al., 2006; Baird et al., 2009). More specifically, during maturation, ecosystems develop in order to increase their activity (T..) and energy storage, and they tend towards greater Ascendency (Ulanowicz, 1997). The highest possible value of Ascendency is called the development capacity (C) which represents the real potential reached by the system in terms of structure. Our results indicated that the ecosystems under a "reef effect" (REEF and COMBINED), seems to be more mature than in the BOWF model and OPTIM scenarios, which agrees with the $P P / R$ and $B / T$.. ratios. However, a high value of Ascendency also means the system is more active in constraining flows along more specific pathways, and so the system can lose flexibility which could lead to an ecosystem with less resilience. Although the Ascendency increased significantly in the "reef effect" scenarios (in the REEF and COMBINED scenarios), the significantly increased redundancy (R) suggest that the ecosystem did not lose its flexibility. The redundancy (or overhead), which is the difference between the internal capacity $(\mathrm{Ci})$ and the internal Ascendency ( $\mathrm{Ai}$ ), is an indicator of the inefficiency of the network (the ecosystem part which is not organised). It measures the number of parallel trophic pathways connecting the different trophic compartments (Ulanowicz and Norden, 1990). The redundancy is based on the idea that within an ecosystem, some species can functionally replace others (McCann, 2000; Woodward, 2009). These 
redundant species can be considered as "guarantors" resulting in a reliable ecosystem functioning (Naeem, 438 1998). Thus redundancy increases the ecosystem resilience as this reservoir of energy acts as an insurance 439 against perturbations (Naeem, 1998 ; Costanza, 1999). The significant increase in both Ascendency and 440 redundancy indicate that after the installation of the OWF, the ecosystem keeps its balance (or equilibrium) 441 between the organised (Ascendency) and non-organised part (redundancy or overhead), which will bring 442 flexibility to potential perturbations as the energy transfers through the trophic network can be maintained 443 via other pathways (Ulanowicz et al., 2009). In addition, according to Mukherjee et al. (2015), the ecosystem 444 after the installation of a OWF seems to be in a healthy state as it "can develop an efficient diversity of 445 components and exchange pathways (high organization) while maintaining some overhead (redundancy) or 446 resilience as insurance against stress".

Adding to this, the TE decreased with TL in the model and scenarios without any interruptions. This indicates that the compartments functionally behaved in a similar way before and after the OWF construction. According to Coll et al. (2009), important perturbations can be detected by analysing the TE profile. In fact, these authors showed that ecosystems undergoing a perturbation such as intense fishing activities, showed breaks in the typical decreasing pattern of TE. This observation of stable TE profiles strengthened our conclusion that the Courseulles-sur-mer OWF construction adds limited stress on the ecosystem. This result can be explained by the fact that the Bay of Seine is historically influenced by a high level of human activities (Dauvin, 2006) may have led to an increased resilience over time to face these multiple pressures (Pezy et al., 2017). However, it is worth noting that our model and simulated scenarios did not take into account all possible effects generated by potential changes in the community, as we chose to use estimates derived from the literature and expert knowledge, and not from complex models. For instance, our simulation did not take into account the potential arrival of invasive species. In fact, some authors suggest that OWF could act as stepping stones for invasive species (Wilhelmsson and Malm, 2008). One example, is the giant chironomid, Telmatogeton japonicus, that have been recorded in the intertidal zone of the wind turbines at Utgrunden, To summarise, ENA indices bring together different holistic indices giving the currently most complete view of an ecosystem approach. They also show a high sensitivity to detect ecosystem changes under different conditions (Dame and Christian, 2007). However, the ecological interpretation remains sometimes complex, as establishing the link between ENA indices and system resilience or maturity (sensu Odum) is still in progress. Thus, the interpretation of their behaviour needs further definitions and contrasted case-studies before they can be useful to characterise ecosystem health and for management purposes. 


\section{Conclusions}

An Ecopath model of the food web flows at the Courseulles-sur-mer OWF site was built allowing to 1) summarize all available ecological data on this site, 2) test different known impacts of OWF at the ecosystem level, 3) investigate the contribution of ENA indices in the assessment of ecosystem health state by confronting them to other indicators commonly-used by the scientific community, and 4) analyse the consequences of potential OWF impacts on ecosystem maturity and resilience through both ENA indices and other ecosystem attributes (Odum, 1969; 1971; Ulanowicz, 1986). Our results revealed a combination of changes in the ecosystem structure and functioning through the analysis of the ENA indices, MTL, and ecosystem attributes. After the installation of the OWF, the ecosystem is expected to be more mature (according to Odum 1969, 1971) while still in a healthy state (according to Mukherjee et al., 2015). Moreover, our study suggested that the small size of the fisheries restriction area would not have any important impact on the ecosystem structure and functioning.

Nonetheless, as marine ecosystems face many natural and anthropogenic perturbations, there is an urgent need to understand how multiple perturbations interact to influence each other and their consequences on ecosystem functioning and stability (Crowe and Frid, 2015; Raoux et al., 2018). Thus, a natural next step would be to develop a holistic view of cumulated impacts within the OWF (Raoux et al, 2018). A qualitative modelling approach (Puccia and Levins, 1986) could suggestively be developed to analyse the ecosystem structure and dynamics, and to take into account ecosystem components and processes that are difficult to measure. This approach could allow to highlight key linkages between the different ecological components and other human dimensions (Dambacher et al., 2015). Integrating cumulative impacts and human dimensions in models fits within the socio-ecosystem approach (Mazé et al., 2015), is part of the field of sustainability sciences dedicated to find concrete applications for coastal management. 
This work was co-funded by the Normandie Region and by the company "Eoliennes Offshore du Calvados" (EOC). This work was part of the project ANTROPOSEINE (G.I.P. Seine-Aval, 5th programme, France) RETROPOLI (aap2015-littoral) and was an introduction to the project Trophik (ANR/FEM EMR-ITE 2015). We also acknowledge, for help in running the ENAtool, Béatrice Charton and Benoist Gaston (Centre Régional Informatique et d'Applications Numériques de Normandie, CRIANN). The authors are also grateful to M.

Haraldsson for revising the English style and grammar.

\section{References}

Ainley, D. G., Pauly, D., 2014. Fishing down the food web of the Antarctic continental shelf and slope. Polar Record, 50(252). https://doi.org/10.1017/S0032247412000757

Arroyo, N.L., Le Loc'h, F., Niquil, N., Preciado, I., Vouriot, P., Safi, G. 2017. Implementation of the Mean Trophic Level Indicator (MTL, FW4) and assessment of its use at a sub-regional level (OSPAR Region IV). EcApRHA Deliverable WP 3.1. OSPAR Commission. 116 pp. http://www.ospar.org/workareas/bdc/ecaprha-dev

Baffreau, A., Pezy, J.P., Dancie, C., Chouquet, B., Hacquebart, P., Poisson, E., Foveau, A., Joncourt, Y., Duhamel, S., Navon, M., Marmin, S., Dauvin, J.C. 2017. Mapping benthic communities: an indispensable tool for the preservation and management of the eco-socio-system in the Bay of Seine. Inter. J. Mar. Sci. 9, 162-173.

Baird, D., Fath, B.D., Ulanowicz, R.E., Asmus, H., Asmus, R., 2009. On the consequences of aggregation and balancing of networks on system properties derived from ecological network analysis. Ecol. Model. 220, 3465-3471.

Bodini, A., 2012. Building a systemic environmental monitoring and indicators for sustainability: what has the ecological network approach to offer? Ecol. Indic.15, 140-148.

Bourdaud, P., Gascuel, D., Bentorcha, A., Brind'Amour, A., 2016. New trophic indicators and target values for an ecosystem-based management of fisheries. Ecol. Indic. 61: $588-601$.

Cabioch, L., Gentil, F., 1975. Distribution des peuplements benthiques dans la partie orientale de la baie de Seine. C. R. Séances Acad. Sci. Paris 280, 571-574.

CBD, 2004. Indicators for assessing progress towards the 2010 target: Marine trophic index. Convention on Biological Diversity. UNEP/CBD/SBSTTA/10/INF/18/ 17 December 2004

Christensen, V., Walters, C.J., 2004. Ecopath with Ecosim: methods, capabilities and limitations. Ecol. Model. 172, 109-139. doi:10.1016/j.ecolmodel.2003.09.003

Christensen, V., Walters, C.J., Pauly, D., Forrest, R., 2008. Ecopath with Ecosim version 6 User Guide. Lensfest Ocean Futures Project 2008 1-235.

Chapin, F. S., Walker, B. H., Hobbs, R. J., Hooper, D. U., Lawton, J. H., Sala, O. E., \& Tilman, D. 1997. Biotic control over the functioning of ecosystems. Science, 277(5325), 500-504. DOI: 10.1126/science.277.5325.500

Coates, D., Deschutter, Y., Vincx, M., \& Vanaverbeke, J. 2014. Enrichment and shifts in macrobenthic assemblages in an offshore wind farm area in the Belgian part of the North Sea. Mar. Environ. Res. 95, 1-12.

Costanza, R., 1999. The ecological, economic, and social importance of the oceans. Ecol. Econ. 31 (2), $199-$ 213.

Coll, M., Palomera, I., Tudela, S. 2009. Decadal changes in a NW Mediterranean Sea food web in relation to fishing exploitation. Ecol. Model. 220, 2088-2102.

Dambacher, J. M., D. J. Gaughan, M.-J. Rochet, P. A. Rossignol, and V. M. Trenkel. 2009. Qualitative modelling and indicators of exploited ecosystems. Fish and Fisheries 10:305-322

Dambacher, J.M., Rothlisberg, P. C., Loneragan, N. 2015. Qualitative mathematical models to support ecosystem-based management of Australia's Northern Prawn Fishery. Ecological Applications, 25(1), 
pp. 278-298.

Dame, J.K., Christian, R.R., 2007. A Statistical Test of Network Analysis: Can it Detect Differences in Food Web Properties? Ecosystems. 10, 906-923. doi:10.1007/s10021-007-9068-1

Dauvin, J.C., 2006. The Seine Estuary, a Highly Developed Area. Seine-Aval Special Issue, September 2006, North Atlantic Estuaries, Problems and Perspectives. pp. 27-32.

Dauvin, J.C., Ruellet, T., Desroy, N., Janson, A.L., 2007. The ecological quality status of the Bay of Seine and the Seine estuary: Use of biotic indices. Mar. Pollut. Bull. 55, 241-257. doi:10.1016/j.marpolbul.2006.04.010

Dauvin, J.C., 2012. Are western and eastern bassin of the English two separate ecosystems. Mar. Pollut. Bull. 64, 463-71

Dauvin, J.C., 2015. History of benthic research in the English Channel: from general patterns of communities to habitat mosaic description. J. Sea. Res. 100, 32-45.

Eliott, S.A.M., Arroyo, N.L., Safi, G., Ostle, C., Guérin, L., McQuatters-Gollop, A., Aubert, A., Artigas, F., Budria, A., Rombouts, I., Pesch, R., Schmitt, P., Vina-Herbon, C., Meakins, B., González-Irusta, J.M., Preciado, I., López- López, L., Punzón, A., Torriente, A., Serrano, A., Haraldsson, M., Capuzzo, E., Claquin, P., Kromkamp, J., Niquil, N., Judd, A., Padegimas, B., Corcoran, E. 2017. Proposed approaches for indicator integration. EcApRHA Deliverable WP 4.1. OSPAR Commission. 43 pp. http://www.ospar.org/workareas/bdc/ecaprha-dev

EU 2008. Directive 2008/56/EC of the European Parliament and of the Council of 17 June 2008 establishing a framework for community action in the field of marine environmental policy (Marine Strategy Framework Directive - MSFD).

EU 2017. Directive 2017/845/EC of 17 May 2017 amending Directive 2008/56/EC of the European Parliament and of the Council as regards the indicative lists of elements to be taken into account for the preparation of marine Strategies.

Finn, J.T. 1980. Flow analysis of models of the Hubbard Brook ecosystem. Ecology 61: 562-571.

Guesnet, V., Lassalle, G., Chaalali, A., Kearney, K., Saint-Béat, B., Karimi, B., Grami, B., Tecchio, S., Niquil. N., Lobry, J. 2015. Incorporating food-web parameter uncertainty into Ecopath-derived ecological network indicators. Ecol. Model. 313, 29-40

Froese, R., Pauly, D., Editors, 2017. FishBase. World Wide Web electronic publication. www.fishbase.org, version (10/2017).

Gascuel, D., Coll, M., Fox, C., Guénette, S., Guitton, J., Kenny, A., Knittweis, L., Nielsen, J.R., Piet, G., Raid, T., Travers-Trolet, M., Shephard, S., 2016. Fishing impact and environmental status in European seas: A diagnosis from stock assessments and ecosystem indicators. Fish Fish. 17, 31-55. https://doi.org/10.1111/faf.12090

Gunderson, L. H. Allen, C. R. Holling, C.S. 2009. Foundations of ecological resilience. Island press.

Groppe, D. M., Urbach, T. P., Kutas, M. 2011. Mass univariate analysis of event-related brain potentials/fields I: A critical tutorial review: Mass univariate analysis of ERPs/ERFs I: Review. Psychophysiology 48: 1711-1725.

Haraldsson, M., Arroyo, N.L., Capuzzo, E., Claquin, P., Kromkamp, J., Niquil, N., Ostle, C., Preciado, I., Safi, G. 2017. Report on the integration of OSPAR Food Webs Indicators into the NEAT tool. EcApRHA Deliverable WP 3.5. OSPAR Commission. 43 pp. http://www.ospar.org/work-areas/bdc/ecaprha-dev

Heymans, J.J., Coll, M., Libralato, S., Morissette, L., Christensen, V., 2014. Global Patterns in Ecological Indicators of Marine Food Webs: A Modelling Approach. Plos one. 9,4. doi.org/10.1371/journal.pone.0095845

Holling, C.S. 1996. Engineering resilience versus ecological resilience. P. Schulze, editor. Engineering within ecological constraints. 31-44.

Köller, J., Köppel, J., Peters, W., 2006. Offshore Wind Energy Research on Environmental Impacts. SpringerVerlag Berlin Heidelberg. pp.371.

Krone, R., Gutow, L., Brey, T., Dannheim, J., Schröder, A. 2013. Mobile demersal megafauna at artificial structures in the German Bight - Likely effects of offshore wind farm development. Estuar. Coast. Shelf Sci. 125, 1-9. doi:10.1016/j.ecss.2013.03.012

Krone, R., Dederer, G., Kanstinger, P., Kramer, P., Scheinder C., Schmalenbach, I. 2017. Mobile demersal megafauna at common offshore wind turbine foundations in the German Bight (North Sea) two years 
after deployment - increased production rate of Cancer pagurus. Mar. Environ. Res. 123, 53-61.

Langhamer, O., 2012. Artificial Reef Effect in relation to Offshore Renewable Energy Conversion: State of the Art. Sci. World J. 2012, 8. doi:10.1100/2012/386713

Latham, L.G., 2006. Network flow analysis algorithms. Ecol. Model. 192, 586-600.

Larsonneur, C., Bouysse, P., Auffret, J.P., 1982. The superficial sediments of the English Channel and its western approaches. Sedimentology. 29, 851-864.

Leonhard, S., Stenberg, C., Støttrup, J., 2011. Effect of the Horns Rev 1 Offshore Wind Farm on Fish Communities Follow-up Seven Years after Construction. DTU Aqua Rep. pp. 99.

Lindeboom, H.J., Kouwenhoven, H.J., Bergman, M.J.N., Bouma, S., Brasseur, S., Daan, R., Fijn, R.C., de Haan, D., Dirksen, S., van Hal, R., Hille Ris Lambers, R., ter Hofstede, R., Krijgsveld, K.L., Leopold, M., Scheidat, M., 2011. Short-term ecological effects of an offshore wind farm in the Dutch coastal zone; a compilation. Environ. Res. Lett. 6, 035101. doi:10.1088/1748-9326/6/3/035101

Lindeman, R.L., 1942. The trophic dynamics aspect of ecology. Ecology. 23, 399-418. doi:10.1017/CBO9781107415324.004

Maar, M., Bolding, K., Petersen, J.K., Hansen, J.L.S., Timmermann, K., 2009. Local effects of blue mussels around turbine foundations in an ecosystem model of Nysted off-shore wind farm, Denmark. J. Sea Res. 62, 159-174. doi:10.1016/j.seares.2009.01.008

Mazé, C., Ragueneau, O., Weisbein, J., Mariat-Roy, E. 2015. Pour une Anthropologie politique de la Mer. Revue internationale d'ethnographie. 5, 189-202.

McCann, K.S., 2000. The diversity-stability debate. Nature 405, 228-233.

Mukherjee, J., Schaler, U.M., Fath, B.D, Ray, S. 2015. Measuring sensitivity of robustness and network indices for an estuarine food web model under perturbations. Ecol. Model. 306, 160-173.

Naeem, S., 1998. Species redundancy and ecosystem reliability. Conserv. Biol. 12, 39-45. doi:10.1111/j.15231739.1998.96379.x

Nichols, T., Hayasaka, S. 2003. Controlling the familywise error rate in functional neuroimaging: a comparative review. Stat Methods Med Res. 12:419-446.

Niquil, N., Le Loc'h, F., Tecchio, S., Chaalali, A., Vouriot, P., Mialet, B., Fizzala, X., Féral, J-P., Lamare, S., Dauvin, J-C., Safi, G., 2014. Ongoing research on ecosystem health indicators for food webs in the MSFD context. Trans-Channel forum proceedings "Science and Governance of the Channel Marine Ecosystem", 14-15. Odum, E.P., 1969. The strategy of ecosystem development. Science 164, 262-270.

Odum, E.P., 1971. Fundamentals of Ecology. W. B. Saunders Co., Philadelphia, USA. 574 pp.

Ortiz, M., Wolff, M., 2002. Trophic models of four benthic communities in Tongoy Bay (Chile): comparative analysis and preliminary assessment of management strategies. J. Exp. Mar. Bio. Ecol. 268, $205-235$. doi:10.1016/S0022-0981(01)00385-9

Palomares, M.L.D., Pauly, D., 2017. SeaLifeBase. World Wide Web electronic publication. www.sealifebase.org, version (10/2017).

Patrício, J., Ulanowicz, R., Pardal, M.A., Marques, J.C., 2006. Ascendency as ecological indicator for environmental quality assessment at the ecosystem level: A case study. Hydrobiologia. 555, 19-30. doi:10.1007/s10750-005-1102-8

Pauly, D., Soriano-Bartz, M., Palomares, M.L., 1993. Improved construction, parameterization and interpretation of steady-state ecosystem models. In: Christensen, V., Pauly, D. (Eds.), Trophic Models of Aquatic Ecosystems. ICLARM Conf. Proc. 26, 1-13.

Pauly, D., Christensen, V., Dalsgaard, J., Froese, R., Torres Jr., F., 1998. Fishing Down Marine Food Webs. JSTOR 279, 860-863.

Pauly, D., Watson, R. 2003. Counting the last fish. SciAm. 289: $42-47$.

Pauly, D., Palomares, M., 2005. Fishing down marine food web: it is far more pervasive than we thought. Bull. Mar. Sci. 76, 197-211. https://doi.org/10.1126/science.279.5352.860

Pinnegar, J.K., Jennings, S., Brien, C.M.O., Polunin, N.V.C., 2002. Long-term changes in the trophic level of the Celtic Sea fish community and fish market price distribution. J. Appl. Ecol. 39, 377-390. https://doi.org/10.1046/j.1365-2664.2002.00723.x

Plaganyi, E.E. 2007. Models for an ecosystem approach to fisheries. FAO Fisheries Technical Paper.477, 108 pp.

Pezy, J.P., Raoux, A., Marmin, S., Balay, P., Niquil, N., Dauvin, J.C. 2017. Before-After analysis of the trophic 
network of an experimental dumping site in the eastern part of the Bay of Seine (English Channel). Mar. Pollut. Bull. 118, 101-111.

Petersen, J.K., Malm, T., 2006. Offshore windmill farms: threats to or possibilities for the marine environment. Ambio 35, 75-80.

Pimm, S.L. 1984. The Balance of Nature, University of Chicago Press, Chicago, IL

Puccia, C.J. and R. Levins. 1985. Qualitative modelling of complex systems. Harvard University Press, Cambridge, Massachusetts.

Polovina, J.J., 1984. Model of a coral reef ecosystem. I. The ECOPATH model and its application to French Frigate Shoals. Coral Reefs. 3, 1-11.

Raoux, A., Tecchio, S., Pezy, J.P., Degraer, S., Wilhelmsson, D., Cachera, M., Ernande, B., Lassalle, G., Leguen, C., Grangeré, K., Le Loc'h, F., Dauvin, J.C., Niquil, N. 2017.Benthic and fish aggregation inside an offshore wind farm: Which effects on the trophic web functioning? Ecol. Indic. 72, 33-46

Raoux, A., Dambacher, J.M., Pezy, J.P., Mazé, C., Dauvin, J.C., Niquil, N. 2018. Assessing cumulative socioecological impacts of offshore wind farm development in the Bay of Seine (English Channel). Marine Policy. 89, 11-20.

Reubens, J.T., Degraer, S., Vincx, M., 2011. Aggregation and feeding behaviour of pouting (Trisopterus luscus) at wind turbines in the Belgian part of the North Sea. Fish. Res. 108, 223-227. doi:10.1016/j.fishres.2010.11.025

Reubens, J.T., Braeckman, U., Vanaverbeke, J., Van Colen, C., Degraer, S., Vincx, M., 2013. Aggregation at windmill artificial reefs: CPUE of Atlantic cod (Gadus morhua) and pouting (Trisopterus luscus) at different habitats in the Belgian part of the North Sea. Fish. Res. 139, 28-34. doi:10.1016/j.fishres.2012.10.011

Rombouts, I., Beaugrand, G., Fizzala, X., Gaill, F., Greenstreet, S.P.R., Lamare, S., Le Loc'h, F., McQuattersGollop, A., Mialet, B., Niquil, N., Percelay, J., Renaud, F., Rossberg, A.G., Férral, J.P., 2013. Food web indicators under the Marine Strategy Framework Directive: From complexity to simplicity? Ecol. Indic. 29, 246-254. doi:10.1016/j.ecolind.2012.12.02

Rybarczyk, H., Elkaïm, B., 2003. An analysis of the trophic network of a macrotidal estuary: The Seine Estuary (Eastern Channel, Normandy, France). Estuar. Coast. Shelf Sci. 58, 775-791. doi:10.1016/S02727714(03)00184-7

Salomon, J.C., Breton, M., 1991. Courants résiduels de marée dans la Manche. Oceanol. Acta. 11, 47-53.

Salomon, J.C., Breton, M., 1993. An atlas of long-term currents in the Channel. Oceanol. Acta. 16, 439-448.

Saint-Béat, B., Baird, D., Asmus, H., Asmus, R., Bacher, C., Pacella, S.R., Johnson, G.A.,David, V., Vézina, A.F., Niquil, N., 2015. Trophic networks: how do theories link ecosystem structure and functioning to stability properties? A review. Ecol.Indic. 52, 458-471.

Shannon, L., Coll, M., Bundy, A, Gascuel, D., Heymans, J., Kleisner, K., Lynam, C., Piroddi, C., Tam, J., TraversTrolet, M., Shin, Y., 2014. Trophic level-based indicators to track fishing impacts across marine ecosystems. Mar. Ecol. Prog. Ser. 512, 115-140. doi:10.3354/meps10821.

Shields, M.A., Payne, A.I.L., 2014. Marine renewable energy technology and environmental interactions, Humanity and the Sea. Springer Sciences. pp. 176.

Tecchio, S., Tous Rius, A., Dauvin, J.-C., Lobry, J., Lassalle, G., Morin, J., Bacq, N., Cachera, M., Chaalali, A., Villanueva, M.C., Niquil, N., 2015. The mosaic of habitats of the Seine estuary: Insights from food-web modelling and network analysis. Ecol. Modell. 312, 91-101. doi:10.1016/j.ecolmodel.2015.05.026

Thurstan, R.H., Brockington, S., Roberts C. M., 2010, The effects of 118 years of industrial fishing on UK bottom trawl fisheries, Nature Communications, 1, http://dx.doi.org/10.1038/ncomms1013.

Tomczak, M.T., Heymans, J.J., Yletyinen, J., Niiranen, S., Otto, S.A., Blenckner, T. 2013. Ecological Network Indicators of Ecosystem Status and Change in the Baltic Sea. PLoS ONE 8, 10, e75439. https://doi.org/10.1371/journal.pone.0075439

Turner, S.J., Thrush, S. F., Hewitt, J.E., Cummings, V.J., Funnel, G. 1999. Fishing impacts and the degradation or loss of habitat structure, Fish. Manag. Ecol. 6, 401-420.

Ulanowicz, R.E., 1986. Growth and Development: Ecosystems Phenomenology. Springer-Verlag, New York

Ulanowicz, R.E., Norden, J.S., 1990. Symmetrical overhead in flown networks. Int. J. Syst. Sci. 1, 429-437.

Ulanowicz, R.E., Abarca-Arenas, L., G., 1997. An informational synthesis of ecosystem structure and function. Ecol. Mod. 95: 1-10. J. Des. Nat. Ecodyn. 42, 83-96. 
698 Ulanowicz, R.E., 1997. Ecology, the Ascendant Perspective. Columbia University Press, New York, USA.

699 Ulanowicz, R.E., 2004. Quantitative methods for ecological network analysis. Comput. Biol. Chem. 28, 321339.

701 Ulanowicz, R.E., Goerner, S.J., Lietaer, B., Gomez, R., 2009. Quantifying sustainability: Resilience, efficiency and the return of information theory. Ecol. Complexity 6, 27-36.

Wilhelmsson, D., Malm, T., 2008. Fouling assemblages on offshore wind power plants and adjacent substrata. Estuar. Coast. Shelf Sci. 79, 459-466. doi:10.1016/j.ecss.2008.04.020

Wilhelmsson, D., Malm, T., Öhman, M.C., 2006. The influence of offshore windpower on demersal fish. ICES 706 J. Mar. Sci. 63, 775-784. doi:10.1016/j.icesjms.2006.02.001 
708

709

710

711

712

713

714

715

716

717

718

Figure 1. Location of the Courseulles-sur-Mer future offshore wind farm (which corresponds to the Ecopath model BOWF) and benthic communities in the Bay of Seine, north-western France (modified from Baffreau et al., 2017).

Figure 2: Differences in compartment throughflows between the three EwE simulations (scenario REEF, OPTIM and COMBINED) and the BOWF model. Note that the $y$-axis scale was log-transformed, and that this percentage analysis did not consider the difference in absolute values between functional groups. Grey bars identified both functional groups for which the biomasses have been set to their accumulated maximum during the Ecosim 30-years simulations of 'reef effect' as well as the functional groups for which a decrease in fishing effort have been set during the Ecosim 30-years simulations 'reserve effect'. Black bars, on the contrary, represented groups for which variations in biomass were an output of the Ecosim simulation across 30 years.

Figure 3. Mean Trophic Level (MTL) and biomass $\left(\mathrm{gC} \cdot \mathrm{m}^{-2}\right)$ of functional groups for the four Ecopath models (BOWF model and OPTIM, REEF and COMBINED scenarios). Three MTL are applied to each scenario (black lines) in order to capture (i) the whole consumers' community (MTL_2.0) with a cut-off of functional groups with $T L<2$; (ii) a focus on higher trophic level species (MTL_3.25) excluding functional groups with $T L<3.25$; and (iii) a focus on top predators (MTL_4.0) excluding functional groups with $T L<4.0$. The functional groups displayed are those who represent $95 \%$ of the total biomass for each cut-off. For interpretation of colours the reader is referred to the online version of the article.

Figure 4. Boxplots of ENA indices for the four Ecopath models (BOWF model and OPTIM, REEF and COMBINED scenarios) using the ENAtool routine, where the median of the distributions was represented by a bold line. Red dots corresponded to the single ENA indices values obtained from the pre-existing Ecopath model using the EwE software. As a validation rule, these single values were all equal to the ENA indices values calculated after the importation of the pre-existing Ecopath model to Matlab with no change on the input parameters. Significant differences ( $p$-value $<0.05$ ) are indicated by letter $a, b$ and $c$.

Figure 5. Transfer efficiencies (TE) by discrete trophic levels for the four Ecopath models (BOWF model and OPTIM, REEF and COMBINED scenarios). 
734 Table 1: Percentages of change applied on input parameters for the pedigree routine in the four Ecopath 735 models (BOWF model and OPTIM, REEF and COMBINED scenarios) in the ENAtool routine. Values 736 corresponded to a percentage of variation around the initial values provided in Table 2. Inv.: invertebrates; 737 B: biomass $\left(\mathrm{gC} \cdot \mathrm{m}^{-2}\right)$; P/B: production to biomass ratio (year $\left.{ }^{-1}\right)$; $\mathrm{Q} / \mathrm{B}$ : consumption to biomass ratio (year ${ }^{-1}$ ); DC: diet composition.

\begin{tabular}{|c|c|c|c|c|c|}
\hline & Compartments & B & $\mathrm{P} / \mathrm{B}$ & Q/B & DC \\
\hline 1 & Bottlenose dolphins & 0.3 & 0.5 & 0.5 & 0.1 \\
\hline 2 & Harbour porpoises & 0.3 & 0.5 & 0.5 & 0.1 \\
\hline 3 & Harbour seals & 0.3 & 0.5 & 0.5 & 0.1 \\
\hline 4 & Grey seals & 0.3 & 0.5 & 0.5 & 0.1 \\
\hline 5 & Diving seabirds & 0.1 & 0.5 & 0.5 & 0.3 \\
\hline 6 & Surface feeders seabirds & 0.1 & 0.5 & 0.5 & 0.3 \\
\hline 7 & Benthopelagic cephalopods & 0.1 & 0.5 & 0.5 & 0.1 \\
\hline 8 & Benthic cephalopods & 0.1 & 0.5 & 0.5 & 0.3 \\
\hline 9 & Fish. mackerel & 0 & 0.5 & 0.5 & 0.3 \\
\hline 10 & Fish. European seabass & 0.1 & 0.5 & 0.5 & 0.3 \\
\hline 11 & Fish. sharks and rays & 0.1 & 0.5 & 0.5 & 0.3 \\
\hline 12 & Fish. Atlantic cod & 0.1 & 0.5 & 0.5 & 0.3 \\
\hline 13 & Fish. whiting & 0.1 & 0.5 & 0.5 & 0.3 \\
\hline 14 & Fish. Atlantic horse mackerel & 0 & 0.5 & 0.5 & 0.3 \\
\hline 15 & Fish. gurnard & 0.1 & 0.5 & 0.5 & 0.3 \\
\hline 16 & Fish. pouting & 0.1 & 0.5 & 0.5 & 0.3 \\
\hline 17 & Fish. poor cod & 0.1 & 0.5 & 0.5 & 0.3 \\
\hline 18 & Fish. European pilchard & 0 & 0.5 & 0.5 & 0.3 \\
\hline 19 & Fish. European sprat & 0 & 0.5 & 0.5 & 0.3 \\
\hline 20 & Fish. piscivorous & 0 & 0.5 & 0.5 & 0.3 \\
\hline 21 & Fish. planktivorous & 0 & 0.5 & 0.5 & 0.3 \\
\hline 22 & Fish. benthos feeders & 0 & 0.5 & 0.5 & 0.3 \\
\hline 23 & Fish. sea bream & 0.1 & 0.5 & 0.5 & 0.3 \\
\hline 24 & Fish. sole & 0 & 0.5 & 0.5 & 0.3 \\
\hline 25 & Fish. European plaice & 0 & 0.5 & 0.5 & 0.3 \\
\hline 26 & Fish. other flatfish & 0 & 0.5 & 0.5 & 0.3 \\
\hline 27 & Benthic inv. predators & 0.1 & 0.5 & 0 & 0.3 \\
\hline 28 & Benthic inv. filter feeders & 0 & 0.5 & 0 & 0.3 \\
\hline 29 & Benthic inv. Bivalves filter feeders & 0.1 & 0.5 & 0 & 0.3 \\
\hline 30 & King scallop & 0.1 & 0.5 & 0 & 0.6 \\
\hline 31 & Benthic inv. deposit feeders & 0 & 0.5 & 0 & 0.3 \\
\hline 32 & Suprabenthos & 0 & 0.5 & 0 & 0.6 \\
\hline 33 & Meiofauna & 0 & 0.3 & 0 & 0.6 \\
\hline 34 & Zooplankton & 0.5 & 0.3 & 0.6 & 0.6 \\
\hline 35 & Bacteria & 0.5 & 0.3 & 0 & 0.6 \\
\hline 36 & Phytoplankton & 0.5 & 0.3 & 0 & 0 \\
\hline 37 & Detritus & 0.5 & 0 & 0 & 0 \\
\hline
\end{tabular}


740 Table 2: Biomass values, trophic level (TL) and Ecotrophic Efficiencies (EE) for the four Ecopath models (i.e.

741 BOWF model and OPTIM, REEF and COMBINED scenarios).

\begin{tabular}{|c|c|c|c|c|c|c|c|c|c|c|c|c|}
\hline \multirow[b]{2}{*}{ Compartments } & \multirow[b]{2}{*}{ BOWF } & \multicolumn{3}{|c|}{ Biomasses $\mathrm{gC} . \mathrm{m}^{-2}$} & \multicolumn{3}{|c|}{ TL } & \multicolumn{5}{|c|}{ EE } \\
\hline & & OPTIM & REEF & COMBINED & BOWF & OPTIM & REEF & COMBINED & BOWF & OPTIM & REEF & COMBINED \\
\hline Bottlenose dolphins & $1.87 \times 10^{-5}$ & $2.1 \times 10^{-5}$ & $8.44 \times 10^{-5}$ & $8.70 \times 10^{-5}$ & 4.76 & 4.77 & 4.76 & 4.72 & 0 & 0 & 0 & 0 \\
\hline Harbour porpoises & $4.10 \times 10^{-4}$ & $4.22 \times 10^{-4}$ & $1.43 \times 10^{-3}$ & $1.49 \times 10^{-3}$ & 4.63 & 4.64 & 4.61 & 4.57 & 0 & 0 & 0 & 0 \\
\hline Harbour seals & $6.73 \times 10^{-4}$ & $6.62 \times 10^{-4}$ & $1.89 \times 10^{-3}$ & $1.89 \times 10^{-3}$ & 4.63 & 4.62 & 4.63 & 4.63 & 0 & 0 & 0 & 0 \\
\hline Grey seals & $2.68 \times 10^{-4}$ & $2.65 \times 10^{-4}$ & $8.73 \times 10^{-4}$ & $8.74 \times 10^{-4}$ & 4.83 & 4.83 & 4.66 & 4.66 & 0 & 0 & 0 & 0 \\
\hline Diving sea birds & $1.50 \times 10^{-2}$ & $1.54 \times 10^{-2}$ & $9.80 \times 10^{-3}$ & $9.72 \times 10^{-3}$ & 3.98 & 3.97 & 3.93 & 3.94 & 0 & 0 & 0 & 0 \\
\hline Surface feeders seabirds & $2.08 \times 10^{-3}$ & $2.14 \times 10^{-3}$ & $1.27 \times 10^{-2}$ & $1.27 \times 10^{-2}$ & 4.07 & 4.06 & 3.95 & 3.95 & 0 & 0 & 0 & 0 \\
\hline Benthopelagic cephalopods & $1.36 \times 10^{-2}$ & $1.88 \times 10^{-2}$ & $1.70 \times 10^{-2}$ & $2.36 \times 10^{-2}$ & 4.07 & 4.13 & 4.14 & 4.17 & 0.43 & 0.43 & 0.63 & 0.44 \\
\hline Benthic cephalopods & $6.22 \times 10^{-3}$ & $6.52 \times 10^{-3}$ & $7.65 \times 10^{-3}$ & $9.48 \times 10^{-3}$ & 3.92 & 3.91 & 3.87 & 3.89 & 0.92 & 0.91 & 0.95 & 0.91 \\
\hline Fish. mackerel & $2.39 \times 10^{-1}$ & $2.73 \times 10^{-1}$ & $2.30 \times 10^{-1}$ & $2.61 \times 10^{-1}$ & 3.14 & 3.14 & 3.10 & 3.10 & 0.99 & 0.99 & 0.99 & 0.99 \\
\hline Fish. European seabass & $1.86 \times 10^{-2}$ & $2.22 \times 10^{-2}$ & $1.63 \times 10^{-2}$ & $1.83 \times 10^{-2}$ & 3.75 & 3.75 & 3.63 & 3.63 & 0.43 & 0.32 & 0.44 & 0.39 \\
\hline Fish. sharks and rays & $1.20 \times 10^{-1}$ & $1.22 \times 10^{-1}$ & $1.64 \times 10^{-1}$ & $1.76 \times 10^{-1}$ & 4.15 & 4.15 & 3.99 & 3.99 & 0.13 & 0.11 & 0.13 & 0.08 \\
\hline Fish. Atlantic cod & $1.97 \times 10^{-2}$ & $1.95 \times 10^{-2}$ & $6.87 \times 10^{-2}$ & $6.87 \times 10^{-2}$ & 4.03 & 4.03 & 4.12 & 4.12 & 0.28 & 0.27 & 0.58 & 0.52 \\
\hline Fish. whiting & $6.80 \times 10^{-3}$ & $6.15 \times 10^{-3}$ & $2.84 \times 10^{-2}$ & $2.84 \times 10^{-2}$ & 4.12 & 4.12 & 4.12 & 4.12 & 0.99 & 0.99 & 0.99 & 0.99 \\
\hline Fish. Atlantic horse mackerel & $1.41 \times 10^{-1}$ & $1.30 \times 10^{-1}$ & $6.36 \times 10^{-2}$ & $5.99 \times 10^{-2}$ & 3.83 & 3.83 & 3.70 & 3.70 & 0.99 & 0.99 & 0.99 & 1.00 \\
\hline Fish. gurnard & $6.30 \times 10^{-3}$ & $6.21 \times 10^{-3}$ & $8.69 \times 10^{-3}$ & $8.67 \times 10^{-3}$ & 3.46 & 3.46 & 3.58 & 3.59 & 0.00 & 0.00 & 0.00 & 0.00 \\
\hline Fish. pouting & 1.66 & 1.64 & 3.85 & 3.85 & 3.76 & 3.76 & 3.31 & 3.30 & 0.04 & 0.04 & 0.10 & 0.10 \\
\hline Fish. poor cod & $8.60 \times 10^{-3}$ & $8.55 \times 10^{-3}$ & $1.64 \times 10^{-3}$ & $1.55 \times 10^{-3}$ & 3.72 & 3.72 & 3.72 & 3.71 & 0.96 & 0.96 & 0.99 & 0.99 \\
\hline Fish. European pilchard & 4.76 & 4.73 & 3.68 & 3.65 & 2.80 & 2.80 & 2.79 & 2.79 & 0.99 & 0.99 & 0.99 & 1.00 \\
\hline Fish. European sprat & $1.08 \times 10^{-1}$ & $1.04 \times 10^{-1}$ & $1.28 \times 10^{-1}$ & $1.30 \times 10^{-1}$ & 3.00 & 3.00 & 3.00 & 3.00 & 0.99 & 0.99 & 0.99 & 0.99 \\
\hline Fish. piscivorous & $2.42 \times 10^{-1}$ & $2.37 \times 10^{-1}$ & $4.86 \times 10^{-3}$ & $3.36 \times 10^{-3}$ & 3.84 & 3.84 & 3.82 & 3.82 & 0.99 & 0.99 & 0.99 & 0.99 \\
\hline Fish. planktivorous & $8.19 \times 10^{-1}$ & $8.13 \times 10^{-1}$ & $7.22 \times 10^{-1}$ & $7.16 \times 10^{-1}$ & 3.01 & 3.01 & 3.00 & 3.00 & 0.99 & 0.99 & 0.99 & 0.99 \\
\hline Fish. benthos feeders & 1.21 & 1.20 & 2.50 & 2.50 & 3.76 & 3.76 & 3.55 & 3.55 & 0.99 & 0.99 & 0.99 & 0.99 \\
\hline Fish. sea bream & $2.98 \times 10^{-2}$ & $2.99 \times 10^{-2}$ & $8.33 \times 10^{-2}$ & $8.61 \times 10^{-2}$ & 3.17 & 3.17 & 3.14 & 3.14 & 0.30 & 0.29 & 0.32 & 0.29 \\
\hline Fish. sole & $5.07 \times 10^{-2}$ & $1.04 \times 10^{-1}$ & $9.80 \times 10^{-2}$ & $9.80 \times 10^{-2}$ & 3.44 & 3.44 & 3.35 & 3.35 & 0.99 & 0.97 & 1.00 & 0.97 \\
\hline Fish. European plaice & $2.16 \times 10^{-2}$ & $4.53 \times 10^{-2}$ & $5.33 \times 10^{-2}$ & $1.24 \times 10^{-1}$ & 3.37 & 3.37 & 3.22 & 3.22 & 0.99 & 0.97 & 0.99 & 0.97 \\
\hline Fish. other flatfish & $6.18 \times 10^{-3}$ & $7.55 \times 10^{-3}$ & $2.70 \times 10^{-2}$ & $2.70 \times 10^{-2}$ & 3.35 & 3.35 & 3.26 & 3.26 & 0.99 & 0.99 & 0.99 & 0.97 \\
\hline Benthic inv. predators & 2.94 & 2.92 & 3.01 & 3.01 & 3.07 & 3.07 & 2.82 & 2.83 & 0.98 & 0.98 & 0.99 & 0.99 \\
\hline Benthic inv. filter feeders & 3.12 & 3.13 & 4.78 & 4.78 & 2.21 & 2.21 & 2.21 & 2.22 & 0.99 & 0.99 & 0.99 & 0.99 \\
\hline $\begin{array}{l}\text { Benthic inv. Bivalves filter } \\
\text { feeders }\end{array}$ & 19.50 & 19.4 & 42.90 & 42.90 & 2.10 & 2.10 & 2.10 & 2.11 & 0.01 & 0.01 & 0.01 & 0.01 \\
\hline King scallop & $7.70 \times 10^{-1}$ & 1.09 & $7.43 \times 10^{-1}$ & 1.09 & 2.10 & 2.10 & 2.04 & 2.11 & 0.58 & 0.37 & 0.59 & 0.39 \\
\hline Benthic inv. deposit feeders & 3.57 & 3.54 & 2.98 & 2.90 & 2.21 & 2.21 & 2.21 & 2.21 & 0.99 & 0.99 & 0.99 & 0.99 \\
\hline Suprabenthos & 2.00 & 2.00 & 1.71 & 1.70 & 2.53 & 2.53 & 2.36 & 2.34 & 0.99 & 0.99 & 0.99 & 0.99 \\
\hline Meiofauna & $9.70 \times 10^{-1}$ & $9.70 \times 10^{-1}$ & 1.06 & 1.06 & 2.10 & 2.10 & 2.10 & 2.10 & 0.99 & 0.99 & 0.99 & 0.99 \\
\hline Zooplankton & 1.72 & 1.71 & 1.79 & 1.79 & 2.00 & 2.00 & 2.00 & 2.00 & 0.88 & 0.88 & 0.99 & 1.00 \\
\hline Bacteria & $7.50 \times 10^{-1}$ & $7.48 \times 10^{-1}$ & $7.70 \times 10^{-1}$ & $7.70 \times 10^{-1}$ & 2.00 & 2.00 & 2.00 & 2.00 & 0.22 & 0.22 & 0.25 & 0.24 \\
\hline Phytoplankton & 3.24 & 3.24 & 3.24 & 3.24 & 1.00 & 1.00 & 1.00 & 1.00 & 0.76 & 0.76 & 0.99 & 0.99 \\
\hline Detritus & 19.00 & 19.00 & 19.00 & 19.00 & 1.00 & 1.00 & 1.00 & 1.00 & 0.49 & 0.49 & 0.8 & 0.83 \\
\hline
\end{tabular}


743 Table 3: Significance level between scenarios for ENA indices using the maximum-statistic method for 744 multiple comparisons (AMI: Average Mutual Information; R/C: relative redundancy; A: ascendency; A/C: 745 relative Ascendency; R: redundancy; FCl: Finn's Cycling Index; T..: Total system Throughput). Significant 746 differences ( $p$-value $<0.05$ ) are indicated in bold.

\begin{tabular}{lccccccc} 
& AMI & R/C & A & A/C & R & FCI & T.. \\
\hline BOWF / OPTIM & 0.696 & 0.430 & 1.000 & 0.971 & 0.920 & 1.000 & 0.997 \\
BOWF / REEF & 0.947 & 0.995 & $\mathbf{0 . 0 0 0}$ & $\mathbf{0 . 0 0 0}$ & $\mathbf{0 . 0 0 0}$ & 0.999 & $\mathbf{0 . 0 0 1}$ \\
BOWF / COMBINED & $\mathbf{0 . 0 1 8}$ & $\mathbf{0 . 0 0 1}$ & $\mathbf{0 . 0 4 1}$ & $\mathbf{0 . 0 0 0}$ & $\mathbf{0 . 0 0 0}$ & 1.000 & 0.530 \\
OPTIM / REEF & 0.112 & 0.742 & $\mathbf{0 . 0 0 1}$ & $\mathbf{0 . 0 0 2}$ & $\mathbf{0 . 0 0 0}$ & 0.986 & $\mathbf{0 . 0 1 7}$ \\
OPTIM / COMBINED & 0.055 & 0.075 & $\mathbf{0 . 0 2 6}$ & $\mathbf{0 . 0 0 0}$ & $\mathbf{0 . 0 0 0}$ & 1.000 & 0.567 \\
REEF / COMBINED & $\mathbf{0 . 0 0 3}$ & $\mathbf{0 . 0 0 1}$ & 0.636 & $\mathbf{0 . 0 0 1}$ & $\mathbf{0 . 0 0 4}$ & 1.000 & 0.864 \\
\hline
\end{tabular}


749 Table 4: Ecosystem attributes (PP/R: total primary production/total system respiration; B/T..: Total 750 Biomass/ Total System Throughputs)

751

\begin{tabular}{lll}
\hline Model and scenarios & $\mathrm{PP} / \mathrm{R}$ & $\begin{array}{l}\mathrm{B} / \mathrm{T} . . \\
\text { (year) }\end{array}$ \\
\hline BOWF model & 1.72 & 0.03 \\
OPTIM scenario & 1.72 & 0.03 \\
REEF scenario & 1.12 & 0.04 \\
COMBINED scenario & 1.12 & 0.04 \\
\hline
\end{tabular}

752

753 
Figure 1.

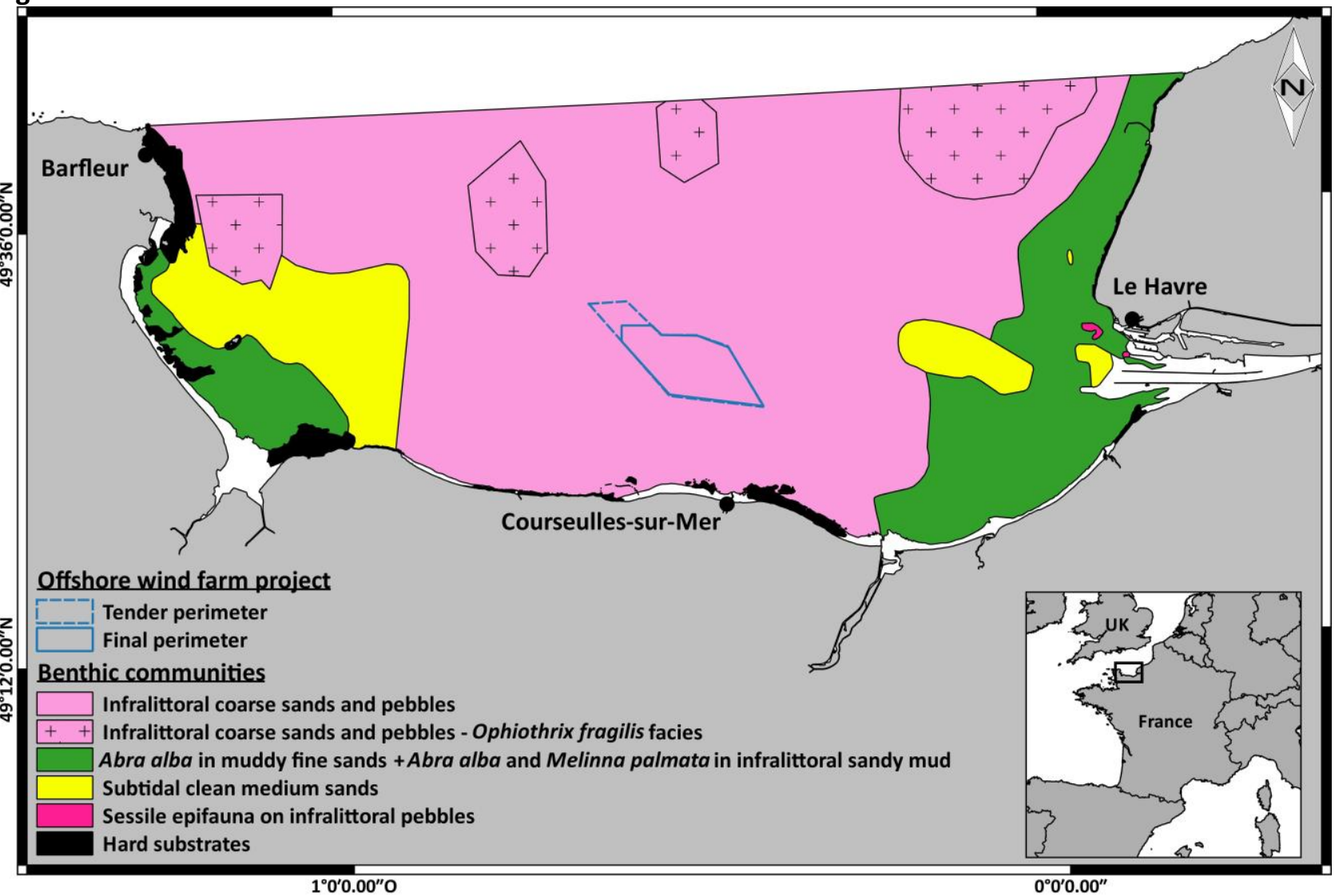


$757 \quad$ Figure 2.
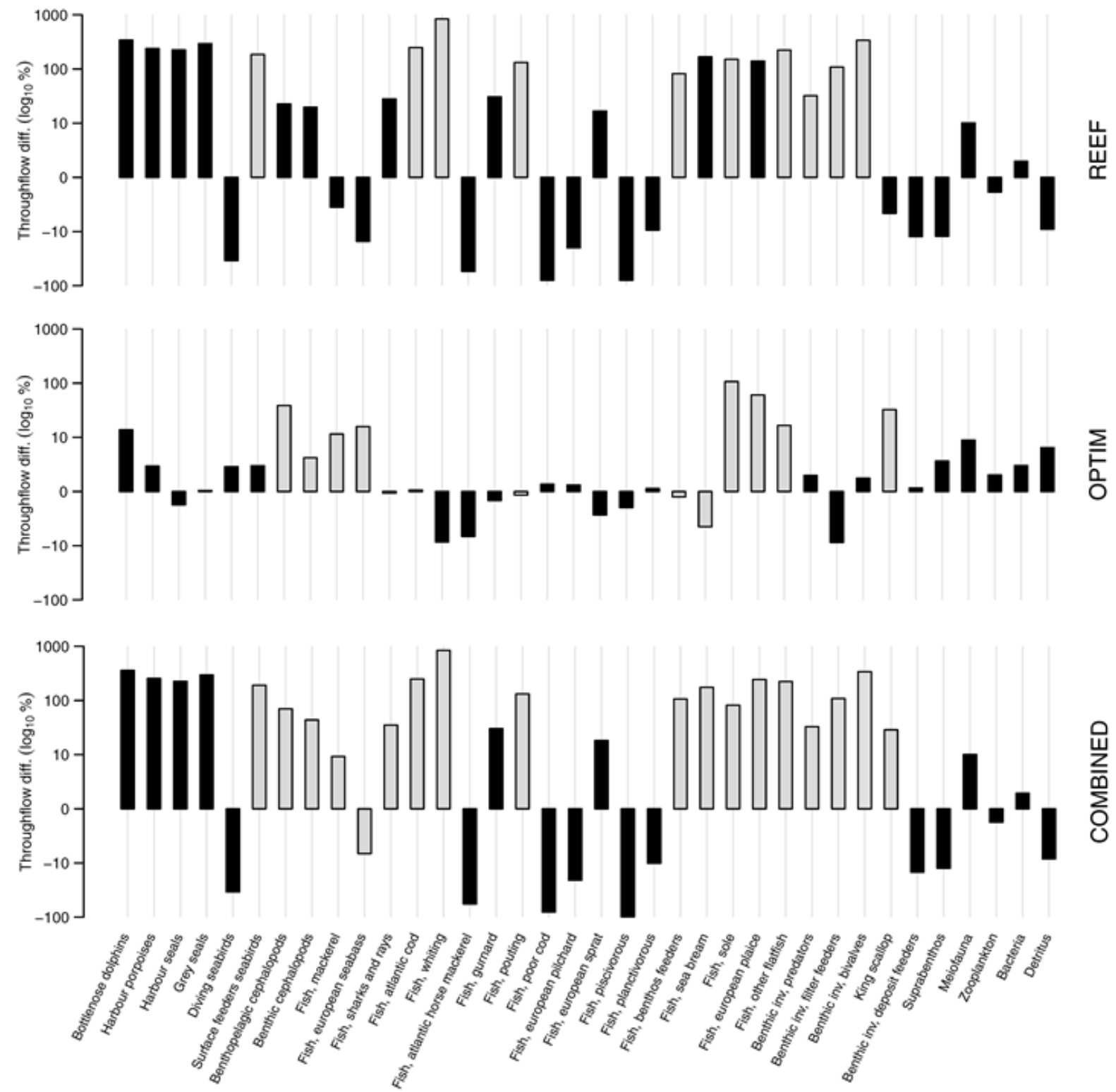
Figure 3.

MTL 2.0
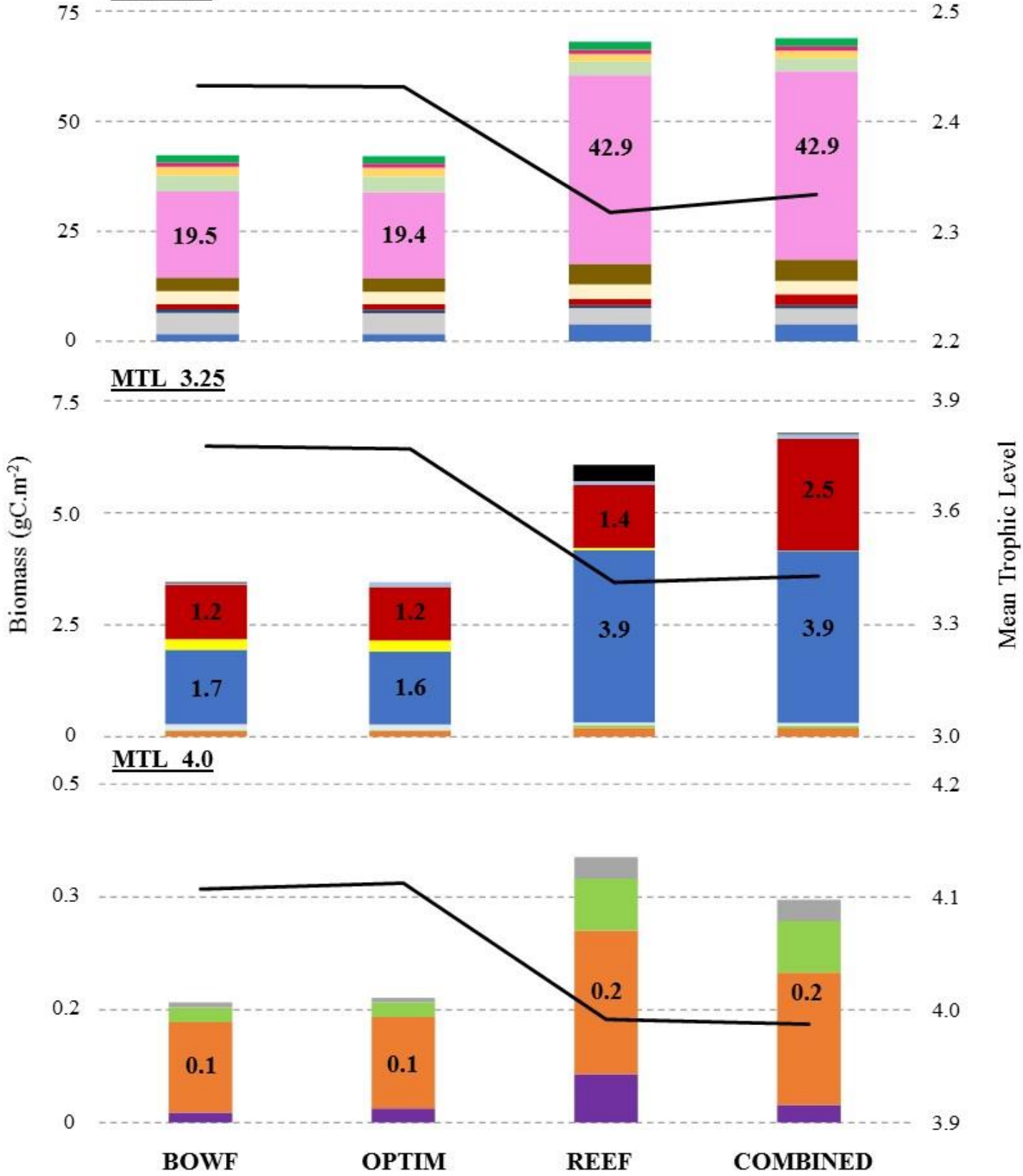

Functional groups

Representing $95 \%$ of total biomass in each cut-off

MTL_3.25
Fish, otherflatfish
Fish, sole
Fish, benthos feeders
Fish, piscivorous
Fish, pouting
Fish, atlantic horse mackerel
Fish, atlantic cod
Fish, sharks and rays

MTL_4.0

Zooplankton

Meiofauna

Suprabenthos

Benthic inv, deposit feeders

Benthic inv, bivalves

Benthic inv, filter feeders Benthic inv, predators

Fish, benthos feeders

Fish, planctivorous

Fish, europe an pilchard

Fish, pouting

\section{Fish, whiting}

Fish, atlantic cod

Fish, sharks and rays

Benthopelagic cephalopods

Fish, atlantic cod

Fish, sharks and rays 
Figure 4.
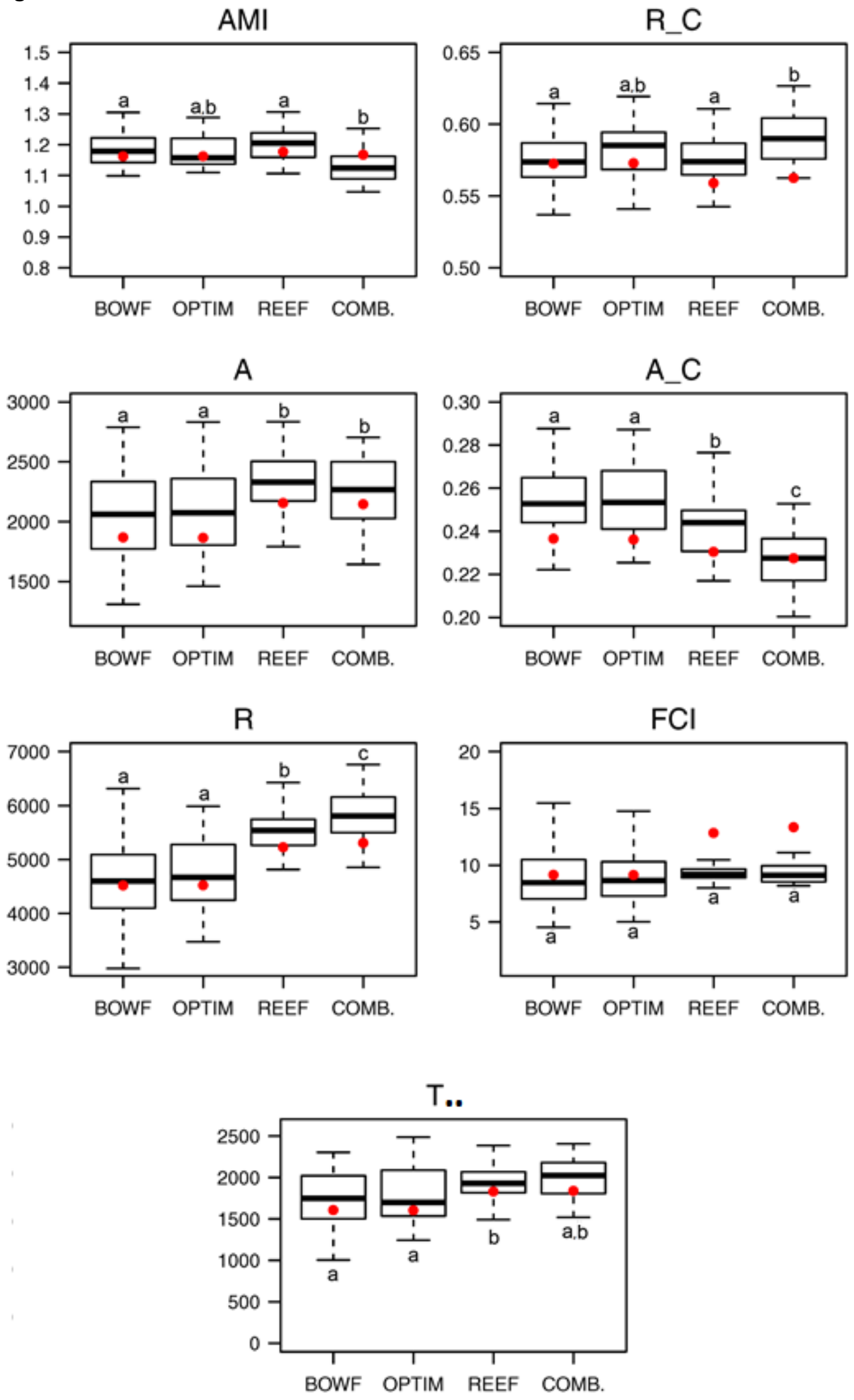
$767 \quad$ Figure 5.

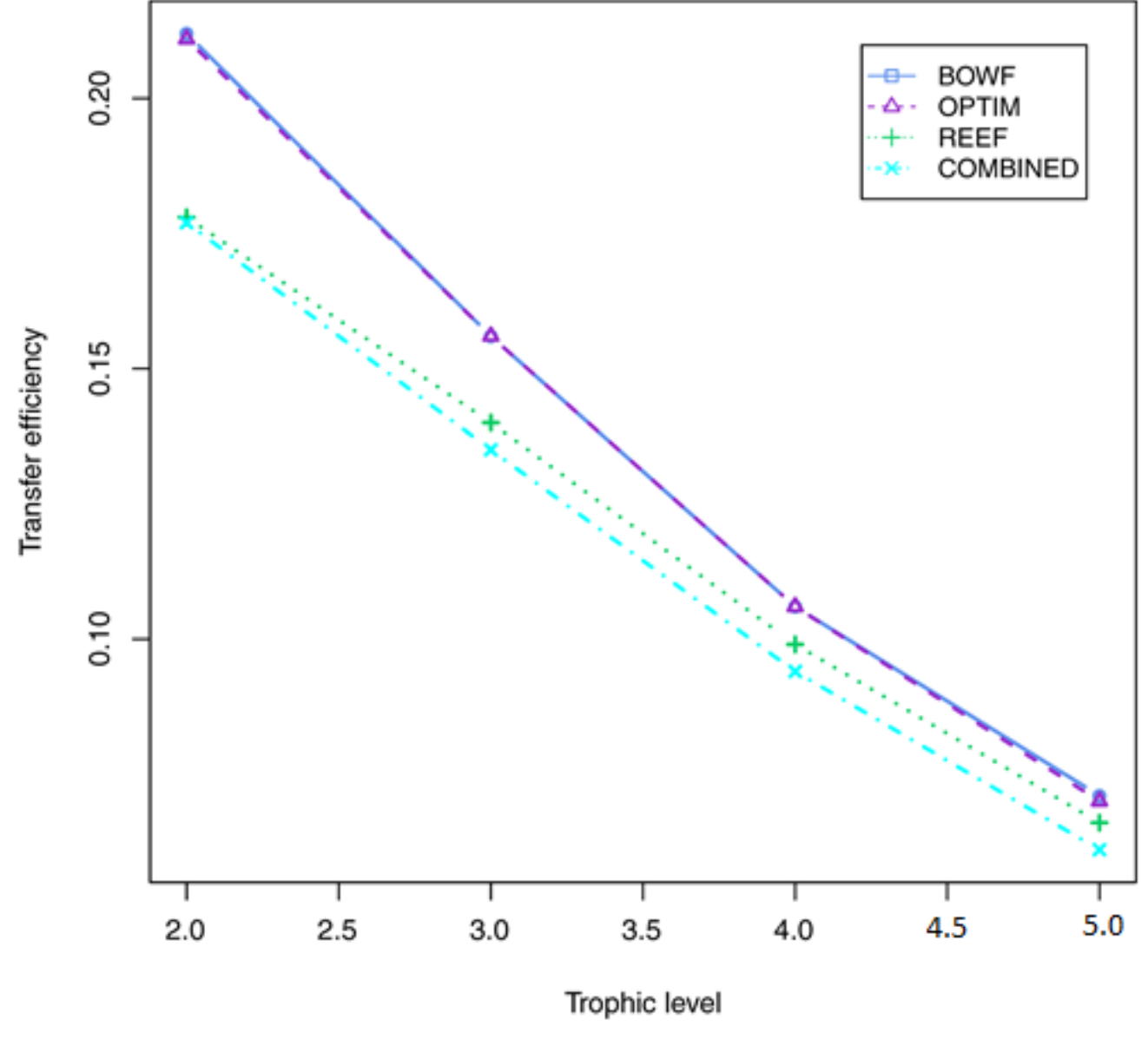

